\title{
A Review of Torque Ripple Minimization Techniques in Switched Reluctance Machine
}

\author{
Ganeish Velmurugan, Serhiy Bozhko, Tao Yang \\ Department of Electrical and Electronic Engineering \\ University of Nottingham, UK \\ eexgv1@nottingham.ac.uk
}

\begin{abstract}
Torque ripple is a major problem in Switched Reluctance Machine (SRM). Despite the high torque ripple and vibration, SRM has many advantages over many other machines. In this paper, the torque ripple minimization control techniques commonly used are reviewed. Torque ripple minimization can be achieved through machine magnetic design or through electronic control. Both techniques have advantages and disadvantages which will be discussed. Torque ripple production is mostly caused by the physical structure of the SRM and the basic principle of its operation. So, the basics of torque production and the physical structure of the SRM is also reviewed as part of this paper.
\end{abstract}

Keywords - Switched Reluctance Machine (SRM), Torque Ripple Minimization, SRM control, SRM design.

\section{INTRODUCTION}

Switched Reluctance Machine is one of the earliest electrical machine that was built - dating back to early $19^{\text {th }}$ century [1]. However, it has not been used in many commercial industrial application until recently. SRM is an electrical machine that converts the reluctance torque into mechanical output. In [1], T.J.E Miller has described the SRM as an electric motor where torque is produced by the tendency of its moveable part (the rotor) to move to the position where the inductance of the winding is maximized. As such the term switched reluctance does not particularly refer to the switching of the reluctance but the switching of the phase current that energizes the stator poles of the machine. Switching of the current phases to alter the reluctance properties of the SRM is the basics of driving the SRM.

Structurally the SRM is known for its simple structure. It is a doubly salient machine and does not contain any permanent magnets unlike Permanent Magnet Machines (PMM) and it only has windings on its stator. As it only contains winding on its stator, it makes the machine a singly excited machine. This results in the cost of manufacturing the SRM to be much lesser than many other commercially available machines. Despite this, the SRM did not get much attention in terms of industrial applications usage. It was only with new technologies and improvement in semiconductor technology that SRM has been gaining new interests.

The primary disadvantage of the SRM is its high torque ripple in comparison to many other conventional machines. The high torque ripple results in high acoustic noise and vibration. The high torque ripple makes the machine not suitable for high-performance application that requires smooth operation [2]. Many recent researches have been focused on developing new techniques to minimize torque ripple in SRM.

Torque ripple minimization in SRM can be achieved through improvement in the machine design and through control strategy developments. Improvements through machine design to minimize torque ripple usually takes a longer time and could possibly result in higher manufacturing cost due to increase in complexity of the machine structure. Minimizing torque ripple through control strategy on the other hand costs much lesser and faster to implement.

In this paper torque ripple minimization techniques used in SRM is reviewed. The paper is structured as follows: In Section II, the basics of SRM such as the structure of SRM and the concepts of torque production is presented. The causes of torque ripple is discussed in Section III. In Section IV, torque ripple minimization techniques through machine design and control strategy improvement are reviewed.

\section{SRM BASICS}

\section{A. Physical Structure of SRM}

The SRM has a very simple structure. It consists of copper windings only at its stator and has no permanent magnet associated with its structure. The stator and rotor design are doubly salient which results in its highly nonlinear behavior and discrete nature of its torque production mechanism. Fig 1 shows the geometric layout of SRM which consists of 6 rotor pole and 4 stator poles (6/4 SRM).

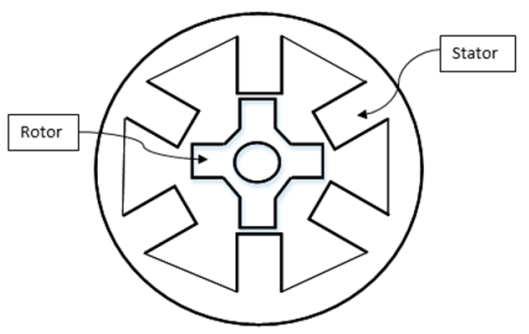

Fig 1 Geometric Layout of a 6/4 SRM

The SRM works on the principle of rotor moving to a position where the inductance of the winding is maximized. The movement of the rotor is controlled by the current commutation sequence through the stator windings where current is pulsated through the stator windings one phase at a time. This is done through a general drive system that consists of the controller and converter. The control of SRM depends on parameters such as the turn-on/turn-off angle, the rotor position and the current reference [3]. Fig 2 illustrates a standard block diagram of SRM Drive.

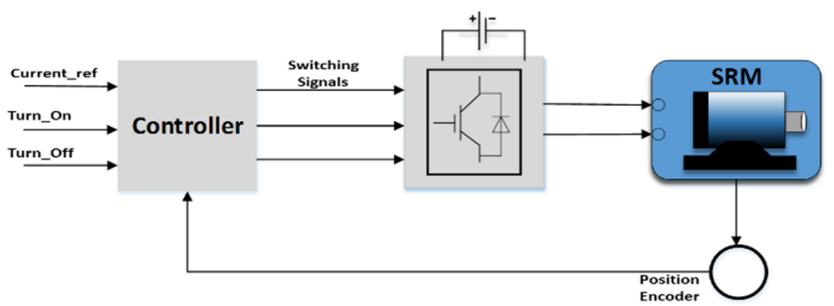

Fig 2 Standard SRM Drive structure 


\section{B. Torque Production in SRM}

Torque produced in each individual SRM phase depends strongly on the rotor position and phase current. This torque per phase, $T_{k}$ is generated by active current phase, $k$ at arbitrary rotor position and phase current can be calculated by finding the partial derivative of magnetic co-energy, $W_{C}$ which is [4]:

$$
T_{k}\left(\theta, i_{k}\right)=\frac{\partial W_{C}\left(\theta, i_{k}\right)}{\partial \theta}, \quad k=1,2,3, \ldots \ldots n
$$

Where $n$ is number of phases of the machine. The magnetic co-energy is defined as,

$$
W_{c}\left(\theta, i_{k}\right)=\int_{0}^{i_{k}} \lambda_{k}\left(\theta, i_{k}\right) d i_{k}
$$

Where $\lambda_{k}$ is the flux linkage per phase which is defined as:

$$
\lambda_{k}\left(\theta, i_{k}\right)=L_{k}\left(\theta, i_{k}\right) i_{k}
$$

$L_{k}$ is the phase inductance and it also varies with the rotor position as well as phase current. The inductance, $L_{k}$ becomes independent of the current, $i_{k}$ by neglecting the saturation field effects in SRM. The torque per phase, $T_{k}$ can then be computed using (1)-(3) as,

$$
T_{k}\left(\theta, i_{k}\right)=\frac{1}{2} \frac{d L_{k}(\theta)}{d \theta} i_{k}^{2}
$$

Eq (4) is defined for torque generated per phase. The total sum of torque generated is defined as

$$
T_{\text {total }}(\theta, i)=\sum_{0}^{k} T_{k}\left(\theta, i_{k}\right)
$$

From (4), as long the inductance slope is positive, the torque produced is always positive is also positive despite the magnitude of the current. Current has a dominant influence on the torque being generated. As such, the shape and commutation of current affects the torque produced by the SRM and it is an important parameter to note in minimizing torque ripple.

\section{CAUSES OF TORQUE RIPPLE}

Various factors are given to causes of torque ripple. From the torque equation in (4), the influence of current in torque production can be seen. The contribution of harmonics in current to torque ripple production is investigated in [5]. Fourier Series analyses is performed to find the dominant current harmonics. It is found the fourth and fifth harmonics have high influence on the torque ripple. Hence, removing these harmonic components and reshaping the current waveform affects the torque produced as well as torque ripple generated by the SRM.

The key factor to the high order of harmonics in the current is due to the need to pulse the current in order to move the rotors. The SRM drive is responsible in sequencing the current based on the rotor position measurement. Due to its doubly salient nature and the lack of permanent magnet in the SRM, only one stator pole pair is active during any cycle. This nature of operation results in torque pulsation behavior in to torque produced in SRM. Torque pulsation has been credited not only to torque ripple but as well as a source of acoustic noise [6].

In short, the discrete nature of the current generated by SRM drive control and the physical nature of the SRM results in the high torque ripple in the SRM. As such, any methodology developed in minimizing torque ripple in SRM needs to focus on improving the current behavior of the SRM drive.

\section{TORQUE RIPPLE MINIMIZATION TECHNIQUES}

There are basically two primary approaches in minimizing torque ripples. Iqbal, $\mathrm{H}$ in [7] has underlined two methods to reduce torque ripples which are:

- Machine Design Improvement

- Control Strategy Improvements

\section{A. Torque Ripple Minimization through Machine Design}

Improving torque ripple in SRM through machine design usually involves modifying the stator and rotor pole geometry. In literature [7], the design steps involved in determining the magnetic design of the SRM is discussed. In this work, the design process defined takes into consideration of tackling the torque ripple and acoustic noise that could be generated.

Based on the machine specification (torque, speed, noise level, etc), the stator and rotor poles geometry are determined using various mathematical equation. Some of the important parameters such as the stator arc, $\beta_{s}$, rotor arc, $\beta_{r}$, which affects the torque ripple are determined. Finite Element Analysis (FEA) tools are then used to verify the magnetic behavior as well as determining the torque ripple and noise generated. In [8], a unique design which involves skewing the rotor poles is presented. The objective of this rotor design is to reduce torque ripple while keeping high torque density. Fig 3(a) shows a conventional rotor and pole design of SRM and Fig 3 (b) is the proposed rotor and stator pole design of SRM in [9].

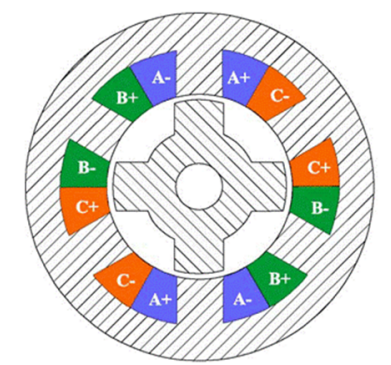

(a)

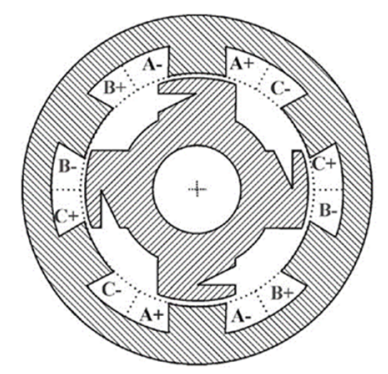

(b)
Fig 3(a) Conventional SRM, (b) Proposed rotor and stator pole design

While this design shows improvement in torque ripple coefficient, no significant improvement was found in terms of torque density. These are one of the drawbacks of torque ripple minimization through magnetic design of SRM where it could result in reduction of the maximum achievable torque due to increased effective airgap through the new geometric design of the rotor/stator poles [10]. 


\section{B. Torque Ripple Minimization through Control Strategy Improvements}

\section{1) Current Profiling}

Torque ripple minimization essentially involves shaping of the current which is performed through profiling of the phase currents. Various current profiling methods have been proposed in many literatures. The differences in the proposed methods are usually in the control algorithm employed in the implementation.

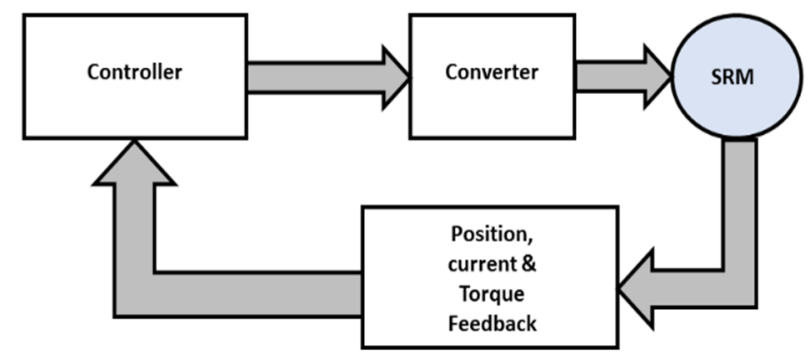

Fig 4 Fine Tuning of Current Profile

The main idea of current profiling is to compute the shape of current through an off-line method to reach zero torque ripple and then the controller is designed to follow the generated current profile [11]. Current profiling uses values of three currents taken from the lookup table of $I=f(T, \theta)$ which is computed for rising current and falling current. When computing the current profile, essentially the torque characteristic is transformed from $T=f(I, \theta)$ to $I=f(T, \theta)$. An initial condition is created from the $T=f(I, \theta)$ lookup table before fine tuning the current profile. Fig 4 shows an illustration of fine tuning of the current profile [12].

Different methods are available in specifying the initial profile. In $[11,12]$, the initial current profile is computed through FEA simulation before fine tuning the current profile with torque feedback as shown in figure. This method takes several iterations depending on the torque ripple requirement before the final current profile is generated. While in [11], a slightly different approach is presented where mathematical equation to compute the max and min current is derived. The current profile is then generated based on the rotor position step and machine current specification. The max and min current are derived as follows [11]:

$$
\begin{gathered}
i_{\max }\left(\theta_{n}\right)=i\left(\theta_{n-1}\right)+\frac{1}{L\left(i\left(\theta_{n-1}\right), \theta_{n-1}\right)} \\
\left(v-i R\left(\theta_{n-1}\right)-\frac{d L\left(i\left(\theta_{n-1}\right), \theta_{n-1}\right)}{d \theta} \omega i\left(\theta_{n-1}\right)\right) d t \\
i_{\text {min }}\left(\theta_{n}\right)=i\left(\theta_{n-1}\right)+\frac{1}{L\left(i\left(\theta_{n-1}\right), \theta_{n-1}\right)} \\
\left(-v-i R\left(\theta_{n-1}\right)-\frac{d L\left(i\left(\theta_{n-1}\right), \theta_{n-1}\right)}{d \theta} \omega i\left(\theta_{n-1}\right)\right) d t
\end{gathered}
$$

The $i_{\max }$ and $i_{\min }$ is used as the limits of the boundary for the new current profile. The new relationship of $I=f(T, \theta)$ is then computed using a current profiling control algorithm. In [11], the current profiling method has successfully reduced the torque ripple to $18 \%$ of the generated average torque. However, the experimental verification was only done for machine speed at $100 \mathrm{rpm}$ which is a low speed operation.

\section{2) Torque Sharing Function}

Torque Sharing Function (TSF) is the most widely reviewed torque ripple minimization technique reviewed in literatures $[4,8,13-15]$. TSF can essentially be thought of as an extension to the current profiling method as it involves signal shaping. Torque is shaped based on the continuously measured position of the rotor angle. Fig 5 below illustrates torque control block with TSF.

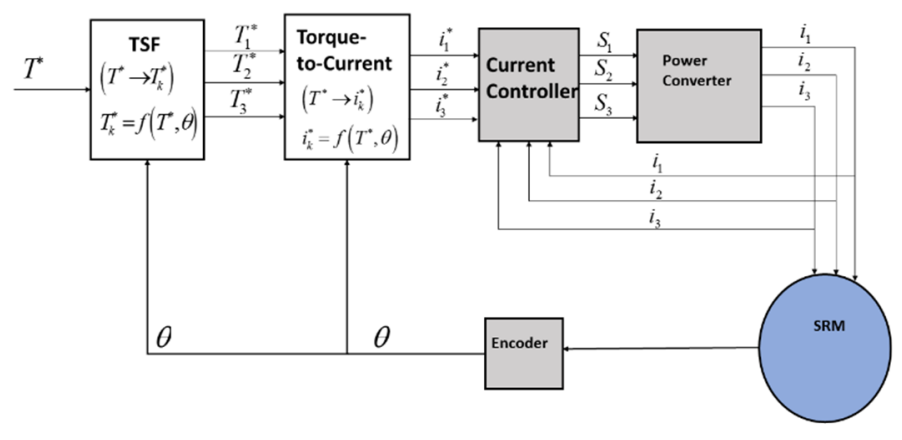

Fig 5 TSF Torque Control Structure

TSFs can be specified to provide ideal torque sharing between individual phases which results in meeting the primary objective of low torque ripple. Some of the commonly used TSFs are based on linear, sinusoidal, cubic or exponential curves. TSF curves are chosen based on the suitability of the TSF defined for the SRM specification and the torque ripple requirement.

\section{Linear TSF}

In defining linear TSF, the torque per phase that is produced during commutation is changing linearly with the rotor position. A linear TSF is defined in [8]. Fig 6 shows the typical profile of the linear TSF.

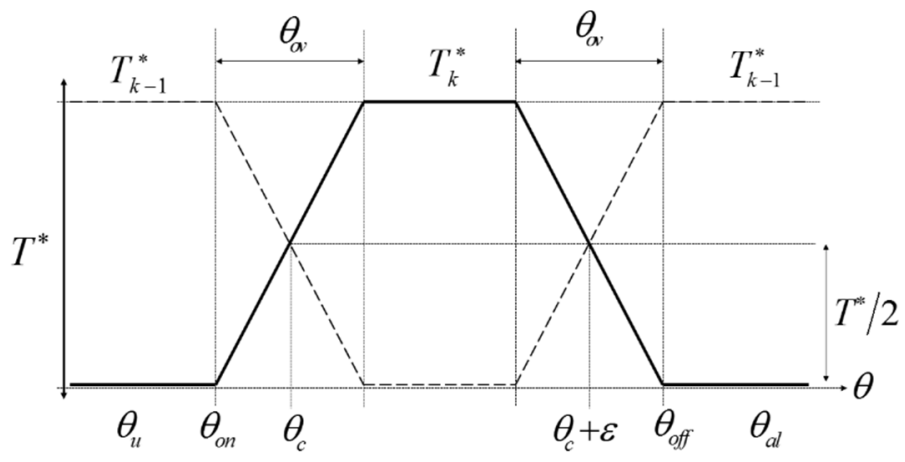

Fig 6 Linear TSF 
The linear TSF can be defined by

$$
T_{k}^{*}(\theta)= \begin{cases}0, & 0 \leq \theta \leq \theta_{o n} \\ T^{*} \cdot f_{\text {rise }}(\theta), & \theta_{o n} \leq \theta \leq \theta_{o n}+\theta_{o v} \\ T^{*}, & \theta_{o n}+\theta_{o v} \leq \theta \leq \theta_{o f f}-\theta_{o v} \\ T^{*} \cdot f_{\text {fall }}(\theta), & \theta_{o f f}-\theta_{o v} \leq \theta \leq \theta_{o f f} \\ 0, & \theta_{o f f} \leq \theta \leq \theta_{a l}\end{cases}
$$

Where $\theta$ is the rotor position, $\theta_{p}$ is the rotor period, $f_{\text {rise }}(\theta)$ is the rising function while $f_{\text {fall }}(\theta)$ is the falling function in the linear TSF. The rising function can be expressed by

$$
f_{\text {rise }}(\theta)=\frac{T^{*}}{\theta_{o v}}\left(\theta-\theta_{o n}\right)
$$

While the falling function can be computed by

$$
f_{\text {fall }}(\theta)=T^{*}-\frac{T^{*}}{\theta_{o v}}\left(\theta-\theta_{\text {off }}\right)
$$

\section{Non-Linear TSF -Sinusoidal TSF}

Sinusoidal TSF is presented in [15]. With the sinusoidal TSF, the curve in the overlap is defined as a sinusoidal function. Fig 7 illustrates the profile of a non-linear sinusoidal TSF.

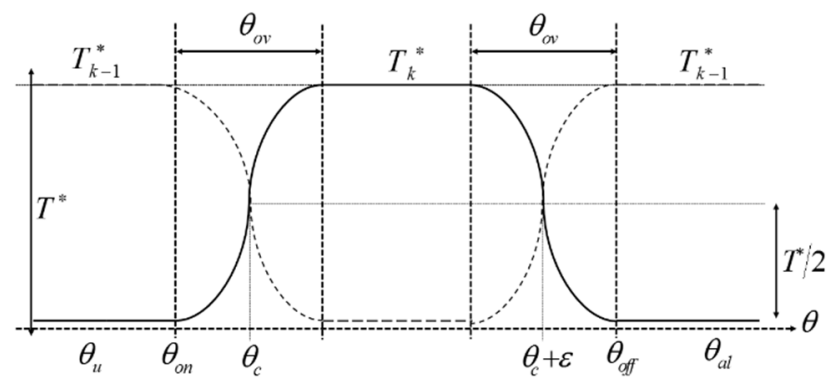

Fig 7 Sinusoidal TSF

The TSF is defined in similar manner as the linear TSF however the rising and falling function in the overlap region is now defined as a sinusoidal function. In [4], this function is defined as

Rising function, $f_{\text {rise }}(\theta)$,

$$
f_{\text {rise }}(\theta)=\left[\sin \left(\frac{\pi}{2}\left(\theta-\theta_{o n}\right) / \theta_{o v}\right)\right]^{2}
$$

Falling function, $f_{\text {fall }}(\theta)$,

$$
f_{\text {fall }}(\theta)=1-f_{\text {rise }}\left(\theta+\theta_{\text {ov }}-\theta_{\text {off }}+\theta_{\text {on }}\right)
$$

In [13], a comparison of Linear TSF and Non-Linear TSFs in terms of torque ripple ratio have been tabulated. It is found that non-linear TSF produces lesser torque ripple even at higher speed of $6000 \mathrm{rpm}$. This is mainly due to the non-linear behavior of the SRM. As such, the torque behavior is better represented using non-linear TSF. The main drawback of the TSF technique is that it requires constant monitoring of the rotor angle. Hence, it requires high precision sensors for exact sensing of rotor position.

\section{3) Direct Instantaneous Torque Control}

Direct Instantaneous Torque Control (DITC) was first proposed in 2003 in [10]. This method presents a torque ripple minimization control which avoids usage of high precision rotor position sensor. In addition, DITC also does not use current or torque profiles and commutating waveforms. The instantaneous torque values are estimated through values measured from the SRM terminal. This addressed the problem of needing an accurate and complex model to express phase current as a function of torque and rotor position [4].

Fig 8 shows a closed loop structure of the DITC block diagram.

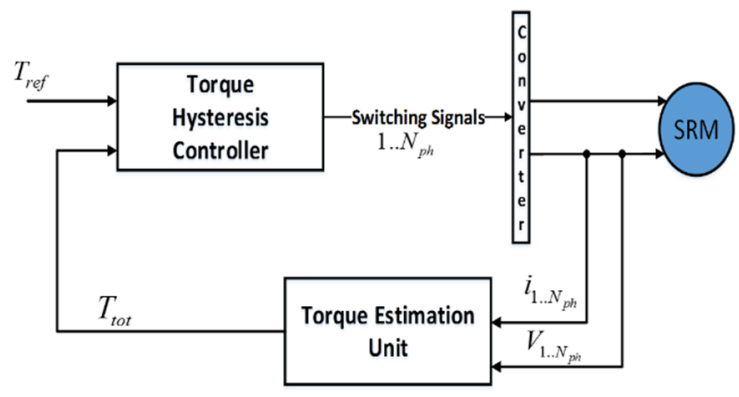

Fig 8 DITC Closed Loop Structure

The torque, $T(\theta, i)$ as defined by (4), depends on current as well as rotor position. To compute accurate torque estimation and for precise control to be performed, accurate continuous rotor position measurement is needed. In the DITC's Torque Estimation Unit (Figure), this is avoided by redefining the torque characteristic as a function of flux linkage instead of rotor position, $T(\lambda, i)$. A look-up table is then generated to compute the Total Torque, $T_{\text {tot }}$ shown in Fig 9 [10].

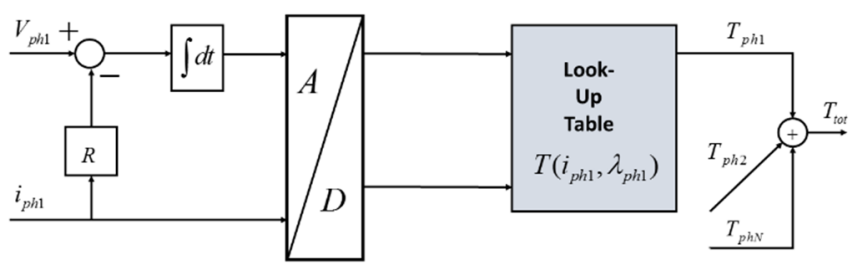

Fig 9 Torque Estimation Unit 
A digital torque hysteresis controller then generates the switching signals for all activated machine phase. Hysteresis controller is also used to obtain high bandwidth of switching signals. Switching strategy needs to be defined for a rather broad range of operation. The implementation of this switching strategy plays an important role in minimizing the torque ripple. In $[10,16]$, the torque pulsations which contributes to torque ripple was largely reduced using DITC. Simulation results showed that torque ripple was reduced to approximately $38 \%$ of the machine average torque of $40 \mathrm{Nm}$.

To conclude, DITC offers a simple control structure with torque ripple minimization. It offers advantage as its independent of rotor position where no torque sharing function needed and direct control of instantaneous torque where no profiling is needed.

\section{4) Intelligent Control - Fuzzy Logic}

Fuzzy logic is a form of artificial intelligent control which has a strong self-learning and adaptive ability. Fuzzy logic control to reduce torque ripple in SRM has been suggested in [17-19]. In principle, fuzzy logic control system is able to approximate relations between variables regardless of the machine characteristics. Fig 10 below shows a block diagram of a fuzzy logic controller for SRM proposed in [17].

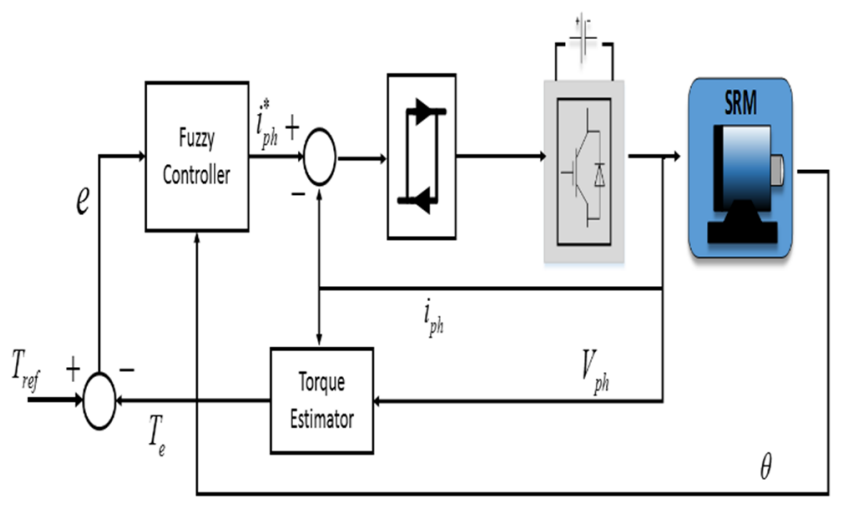

Fig 10 A Fuzzy Logic Controller in SRM

The rotor position and phase currents are employed as input and output for the controller. The torque estimator estimates the instantaneous torque which is used to determine the membership distribution of the fuzzy controller. In [17], the fuzzy logic controller is claimed to be able to generate a smooth torque over the rated speed as well as being robust to errors in the rotor position.

The main advantage of using fuzzy logic controller is that it does not need an analytical model of the system and are very suitable for nonlinear systems, besides it does not rely on machine parameters. However the main drawback has been developing the complex computational algorithm of the fuzzy logic.

\section{CONCLUSION}

Torque ripple has been a major drawback in SRM for commercial operation. Torque ripple which results in high vibration and acoustic noise may not be a viable aspect of the SRM for high performance applications. As such minimizing torque ripple in the SRM is essential for SRM operation in commercial applications. Torque ripple can be minimized through improving the machine design as presented in this paper. However, torque ripple minimization through machine design changes increases the structural complexity which results in production cost increase while also possibly reducing the maximum achievable torque. Torque ripple minimization through control strategy provides a more costeffective and flexible choice in dealing with torque ripple. Various control strategy method common used in torque ripple minimization has been presented and reviewed in this paper. Each presented method provides improvement in torque ripple produced by the SRM. Despite the amount of work done in reducing the torque ripple, there are still areas of the SRM operation where the torque ripple has not been well studied yet. The presented torque ripple minimization techniques focuses in reducing torque ripple when the SRM is operating in motoring mode. Control techniques to reduce torque ripples when the SRM is in generation mode is an area where more research is still required to be done.

\section{REFERENCES}

[1] T. J. E. Miller, Electronic Control of Switched Reluctance Machines. Oxford: Newnes 2001.

[2] A. K. I. Husain, "A Fourier Series Generalized Geometry-Based Analytical Model of Switched Reluctance Machines," IEEE Transactions on Industry Applications, vol. Vol.43, May/June 2007.

[3] D. A. Torrey, "Switched reluctance generators and their control," IEEE Transactions on Industrial Electronics, vol. vol. 49, pp. pp. 3-14, Feb 2002.

[4] V. P. Vuji 'ci', "Minimization of Torque Ripple and Copper Losses in Switched Reluctance Drive," IEEE Transactions on Power Electronics, vol. vol. 27, pp. pp. 388-399, Jan. 2012.

[5] B. L. Z. Q. Zhu, L. Huang and W. Chu, "Contribution of Current Harmonics to Average Torque and Torque Ripple in Switched Reluctance Machines," IEEE Transactions on Magnetics, vol. vol. 53, pp. pp. 1-9, March 2017.

[6] E. A. a. A. N. H. Khalili, "Torque ripple minimization in SRM drives using phase/current profiles," presented at the 2007 International Aegean Conference on Electrical Machines and Power Electronics, Bodrum, 2007.

[7] I. H. M. N. Anwar, A. V. Radun, "A comprehensive design methodology for switched reluctance machines," IEEE Transactions on Industry Applications, vol. vol. 37, pp. pp. 1684-1692, Nov/Dec 2001.

[8] K. W. E. C. a. S. L. H. X. D. Xue, "Optimization and Evaluation of Torque-Sharing Functions for Torque Ripple Minimization in Switched Reluctance Motor Drives," IEEE Transactions on Power Electronics, vol. 24, pp. 2076-2090, Sept. 2009.

J. O. G. Li, S. Hlioui, E. Hoang, M. Lecrivain and M. Gabsi, "Modification in Rotor Pole Geometry of Mutually Coupled Switched Reluctance Machine for Torque Ripple Mitigating," IEEE Transactions on Magnetics, vol. 48, pp. 2025-2034, June 2012.

[10] R. W. A. A. D. D. Robert B. Inderka, "DITC-Direct Instantaneous Torque Control of Switched Reluctance Drives," IEEE TRANSACTIONS ON 
INDUSTRY APPLICATIONS, vol. VOL. 39, JULY/AUGUST 2003.

[11] P. R. P. Dúbravka, P. Makyš and L. Szabó, "Control of switched reluctance motor by current profiling under normal and open phase operating condition," IET Electric Power Applications, vol. 11, pp. 548556, April 2017.

[12] I. H. R. Mikail, Y. Sozer, M. S. Islam and T. Sebastian, "Torque-Ripple Minimization of Switched Reluctance Machines Through Current Profiling," IEEE Transactions on Industry Applications, vol. 49, pp. 1258-1267, May-June 2013.

[13] M. Q. Ye Wei, Zhang Poming, Guo Yangyang, "Torque Ripple Reduction in Switched Reluctance Motor Using a Novel Torque Sharing Function," presented at the 2016 IEEE/CSAA International Conference on Aircraft Utility Systems (AUS), Beijing,China, ,2016.

[14] K. W. E. C. X. D. Xue, S.L. Ho, "A Control Scheme of Torque Ripple Minimization for SRM Drives Based on Flux Linkage Controller and Torque Sharing Function," presented at the 2006 2nd International Conference on Power Electronics Systems and Applications, Hong Kong, 2006.

[15] M. E. I. Husain, "Torque ripple minimization in switched reluctance motor drives by PWM current control," IEEE Transactions on Power Electronics, vol. vol. 11, pp. pp. 83-88, Jan 1996.

[16] A. H. A. Klein-Hessling, R. W. De Doncker, "Direct instantaneous torque and force control: A novel control approach for switched reluctance machines," presented at the 2015 IEEE International Electric Machines \& Drives Conference (IEMDC), Coeur d'Alene, ID, , 2015.

[17] M. E. a. I. H. S. Mir, "Torque-ripple minimization in switched reluctance motors using adaptive fuzzy control," IEEE Transactions on Industry Applications, vol. 35, pp. 461-468, Mar/Apr 1999.

[18] J. S. A.-S. J. A. Domínguez-Navarro, H. A. Pascual and J. L. Bernal-Agustín, "Fuzzy-logic strategy control for switched reluctance machine," presented at the 2018 Thirteenth International Conference on Ecological Vehicles and Renewable Energies (EVER), Monte-Carlo, 2018.

[19] M. D. a. A. Dadpour, "Radial force and torque ripple optimization for acoustic noise reduction of SRM drives via fuzzy logic control," presented at the 2010 9th IEEE/IAS International Conference on Industry Applications - INDUSCON 2010, Sao Paulo, 2010. 